\title{
Impact of Work Related Stress on Motion Stereotypic Responses
}

\author{
Monalisha Banerjee ${ }^{1}$, Alakananda De ${ }^{1}$, Prakash Chandra Dhara ${ }^{1 *}$
}

\section{ABSTRACT}

Stereotypes can be referred as conditioned reflexes which have become subconscious and automatic. In the present study efforts have been made to figure out how work stress affects motion stereotype. The study was performed on a group of pole manufacturing workers $(n=44)$ having the age group of 45-54 years. The work related stress was evaluated in terms of CSI (Cardiovascular Stress Index) of the subjects on the basis of their heart rates. The subjects were divided into three groups (light stress, moderate stress and high stress) according to the percentile values of CSI. Direction of motion stereotype was determined for different controldisplay units, viz., rotary control knob and horizontal display, rotary control knob and vertical display, rotary control knob and circular display, and rocker switch in horizontal and vertical alignment for 'on' and 'off' response. Index of reversibility of the direction of motion stereotype was determined. Experiments were also performed for right and left handed workers separately. The response initiation time of the workers was computed by a digital timer. Results showed that there was no significant difference in the direction of motion stereotype between left and right handed workers. Significant difference ( $<<0.05$ or less) in the direction of motion stereotype of the workers was observed in most of the control display combinations among different stress levels. The index of reversibility was decreased with increased stress level. It may be concluded that work related stress had a notable effect on motion stereotypic responses of the factory workers.

Keywords: Work stress, CSI, Motion Stereotype, Index of Reversibility.

Physiological or biological stress can be defined as an organism's response towards a stressor that is a stress factor, which can be an environmental condition or a stimulus. In general the more stressors one experience at a time, the more stressed he /she feels. Stressor is a mediator or a stimulus that can cause stress. Stress can have a lot of deep impact on the human biological systems. Chronic stress that is long term stress can have harmful effects on health (Charmandari et. al., 2005). Stress may be a negative or a positive condition that can have a powerful impact on mental and physical well- being. Acute stress that is a little bit of stress that keeps us active and

\footnotetext{
${ }^{1}$ Department of Human Physiology with Community Health, Vidyasagar University, Midnapore, West Bengal *Responding Author (C) 2016 I M Banerjee, A De, P Dhara; licensee IJIP. This is an Open Access Research distributed under the terms of the Creative Commons Attribution License (http://creativecommons.org/licenses/by/2.0), which permits unrestricted use, distribution, and reproduction in any Medium, provided the original work is properly cited.
} 
alert. In response to a stressful incident the human system acts accordingly by the activation of sympathetic nervous system which in turn initiates the fight-or-flight response, during this period body produces larger amounts of the chemicals adrenaline, nor adrenaline and cortical, which trigger a higher heart rate, sharp muscle attentiveness, sweating, and alertness - these factors help us guard ourselves in challenging circumstances (Lupien et al., 2006). Human body cannot be in stressed condition for long time; the parasympathetic system acts and restores the body's normal physiological conditions by homeostasis (Goldstein and Kopin, 2007). There are majorly four types of effects of stress which is cognitive, emotional, physical and behavioral.

Stress has a psychological basis but it affects a number of physiological processes including electro dermal activity, heart rate, blood pressure, muscle tension, and respiration (Dawans et. al., 2011; Vrijkotte, et al., 2000; Lundberg, et al., 1996)

According to WHO a healthy workplace is one where the workers and manager collaborate to use a continual procedure to promote the health, safety and well-being of the workers and to save them. There are different psychosocial, physical and chemical factors, which can influence the human being on the workplace are termed as stress factors which affect the central nervous system. Small workplaces (less tthan 50 employees) have lowest prevalance rate of work related stress (Health and Safety Executive, 2015), According to Houtman and his collaborators (1994), work stressors were highly correlated with psychosomatic complaints, general health, fatigue and boredom at work. According to Smith and colleagues (2000) Full-time workers are more prone to suffer from work related stress than the part-time workers.

In work places the workers require to use control- display units for performing different tasks. During operation of any control-display unit human being has their own expectations regarding the action of the controls which may vary person to person, population to population and situation to situation. This is known as motion stereotype. Motion Stereotype is a cognitive process. Stereotypes are conditioned reflexes which have become subconscious and 'automatic' (Kroemer and Grandjean, 1997). Stereotypes also differ in repetitiveness and inflexibility. Control-display combinations are the primary means by which users interact with machines and equipment, these combinations must be designed according to the response preferences of the user population for a successful man-machine interaction. The idea of implicating population stereotypes into interface design is that a given movement of a control switch should result in the most expected movement of the corresponding display (Courtney, 1994a). Control-display units which are designed with established population stereotypes taken into consideration are found to be supporting higher and consistent performance of the users yielding lesser stress and fatigue (Chan et al., 2003), confusion from the user end is also found to be decreased (Chan et al., 2007a).

There are many suggested stereotypes in the field of man-machine interface design; these stereotypes take account of the Warrick's principle, clockwise-to-increase or anything principle, and the scale-side principle (Courtney, 1994b). However, these principles do not apply in situations 
where the control needs to release any substance which is under pressure. For example, increasing water flow is achieved by moving the tap anticlockwise and the knob on a gas stove is also turned anticlockwise to increase the gas flow (Petropoulos \& Brebner, 1981).

According to previous researchers the reversibility of any given population stereotype may be essential for evaluating the effectiveness of a control-display set up. For example, perfect reversibility is accomplished when the OFF response is just opposite of the ON response. That is, if turning a control knob or switch clockwise is designated to raise an indicator on a scale, then moving that same control knob or switch anticlockwise would make the indicator go down on the scale. Reversibility of an interface is often rated according to the Index of Reversibility (IR). The IR is an index which ranges from a value of 0 (non-reversibility) to a value of 1 (perfect reversibility). When a control-display configuration is found to be reversible, it may be said that the population stereotypes in effect are strong and the users can clearly manipulate the given control for the desired movement of the display.

Hand preference or handedness has dominant impact on hand skill and relation to brain function (Corballis, 2003). Handedness can be viewed from three different aspects: a) the relative preference for one hand in the execution of various unimanual tasks (Peters, 1998); b) the greater skillfulness of the hand in the performance of these tasks (Peters, 1998); and c) the greatest strength of one hand (Bowman and Katz, 1984; Chau et al., 1997).

The present study was aimed to find out the effects of work related stress on motion stereotypic responses of both left and right handed subjects. To fulfill the aim we evaluated the effect of post work stress on motion stereotypic responses on some factory workers. As the evidence of stress after work, we measured heart rate and compared it with the same parameter measured during rest. We studied response preferences, response initiation time and index of reversibility for operating some simple control display units at different stress levels (light, moderate and high).

\section{PARTICIPANTS AND METHODS}

The study was conducted on 44 adult male factory (Pole manufacturing) workers of East Midnapore district of West Bengal, aged between 45-54 years. The said age group of the workers was selected because according to a report of Health and Safety Executive (2015), this age group had highest prevalence rate of work related stress. Ethical approval and prior permission was obtained from the Institutional Ethics Committee before commencement of the study. The study was performed in accordance with the ethical standards of the committee and with the Helsinki Declaration. Prior to the experimental trial, the subjects were approached and the protocol of the study was explained in local language (Bengali). Informed consent was also obtained from each participant.

\section{Evaluation of handedness:}

The handedness of the subject was evaluated on the basis of "the greatest strength of one hand" principle (Bowman and Katz, 1984; Chau et al., 1997). The hand grip strength of the workers 
was measured by a hand grip dynamometer (Laffety, USA). The hand which had greatest strength was considered to be the dominant hand. i.e., if the left hand of any subject scored higher grip strength than the right hand, the subject was considered to be left handed.

\section{Assessment of work related stress using physiological indicators:}

In this study we measured heart rate as the evidence of work related stress (after 3 - 4 hours of work).

\subsection{Measurement of heart rate:}

The resting and working heart rate of the subjects were measured by a heart rate monitor. The resting heart rate of the subjects was measured under sitting condition 30 minutes before the beginning of their scheduled work at factory. The working heart rate of the subjects was recorded every one hour interval for the entire working period and the mean value was expressed as the working heart rate.

\subsection{Evaluation of CSI:}

Cardiovascular stress index (CSI) is a good parameter for measuring the level of stress imposed on the human due to work. It is determined by the following formula (Trites et.al., 1993).

$100 *$ (Heart rate during work - Resting heart rate)

$\mathrm{CSI}=$

$$
\text { Max. Heart rate - Resting heart rate }
$$

(Max. Heart Rate $=220$-Age in years)

The subjects were further divided into three categories according to the level of cardiovascular stress. The percentile values of CSI were used to categorize them as shown in Table 1.

Table 1: classification stress according to CSI

\begin{tabular}{|l|l|}
\hline CSI values Up to $35^{\text {th }}$ percentile & Light stress \\
\hline $\begin{array}{l}\text { CSI values from } 36^{\text {th }} \text { to } \mathbf{7 0}^{\text {th }} \\
\text { percentile }\end{array}$ & Moderate stress \\
\hline CSI values above $7^{\text {th }}$ percentile & High stress \\
\hline
\end{tabular}

\section{Determination of control response stereotype:}

Simulation of control-display combination:

Different combinations of control and displays were simulated for performing the experiments. Some simple analog displays (vertical, horizontal and semicircular) with different controls (rotary switches and rocker switches) were set on wooden / Bakelite box separately for each combination of control and display. The following combinations were made: 


\subsection{Rotary motion switches and display combinations:}

The motion stereotype of the subject was studied by using a rotary switch and an analog display. Three systems were made for this purpose:

(A) A rotary control knob and an analog display system in which an indicator moves in horizontal direction.

(B) A rotary control knob and an analog display system in which an indicator moves in vertical direction.

(C) A control knob and an analog display system in which an indicator moves in circular pattern.

The subjects were asked to operate the control knob to cause a movement of the indicator in a particular direction (left or right, and up or down). The subject's effort to rotate the control knob (either clockwise or counterclockwise) for desired movement of display indicator was recorded. In case of semicircular display, the subjects were asked to move the display pointer for increasing (or decreasing) the scale.

\subsection{Operation of rocker switches for on response:}

Rocker switches were connected to the electric lights. The switches were aligned in two directions: (A) vertical (B) horizontal.

The subjects were asked to operate the switch to make the light on or off. They have to press the switch to make the lower end depressed or upper end depressed (while the other end will remain raised) in the first case and in the second case it is required to press the switch to make the right end depressed or left end depresses (while the other end will remain raised). The mode of operation of the subjects was recorded.

\section{Index of reversibility:}

Reversibility of stereotypes is a great issue for designing of different control systems. In case of movement compatibility, reversibility is a phrase which describes the situation where, a subject who turns a control clockwise to increase the display value will also turn the control anticlockwise to decrease the display value to the target value (Chan \& Chan, 2007b). Previous studies on movement compatibility confirm that an operator's expectations are not for all the time reversible. The index value ranges from a value of 0 which indicates absolute nonreversibility to a value of 1 for perfect reversibility, it will occur when the response to 'increasing instruction' is opposite to the response to 'decreasing instruction' (Chan \& Chan, 2007b). The index of reversibility (IR) was calculated with the help of the sum of two products. One product was obtained from the proportion of clockwise-for-increase (CI) and anticlockwise-for-decrease (AD) responses, and the other from the proportion of the opposite pair of anticlockwise-forincrease (AI) and clockwise-for-decrease (CD) responses (Chan and Chan, 2007b).

$$
\mathrm{IR}=\mathrm{p}(\mathrm{CI}) \mathrm{p}(\mathrm{AD})+\mathrm{p}(\mathrm{CD}) \mathrm{p}(\mathrm{AI})
$$

Here 'p' was the proportion (A proportion was a name we give to a statement that two ratios were equal.) 
$\mathrm{p}(\mathrm{CI})=$ sum of clockwise to increase (right) response $\div$ total no. of subjects took part in the study Likewise,

$p(A D)=$ sum of anti clockwise to decrease (left) response $\div$ total no. of subjects took part in the study

$\mathrm{p}(\mathrm{CD})=$ sum of clockwise to decrease (left) response $\div$ total no. of subjects took part in the study

$\mathrm{p}(\mathrm{AI})=$ sum of anti clockwise to increase (right) response $\div$ total no. of subjects took part in the study.

\section{Response initiation time:}

The time between stimulus and the beginning of movement, was used as an index of the difficulty of information processing. Digital timer was used for recording response initiation time (RIT) for different combination of control and displays.

\section{STATISTICAL ANALYSIS}

A classification of CSI was done by calculating $35^{\text {th }}$ and $70^{\text {th }}$ percentile values from the calculated experimental CSI values of the subjects using MS Excel. To test the significance of association of different response types in different stress levels Chi Square Test was performed, for testing significant difference of mean of different parameters such as heart rate, hand grip strength Student's t test and for response initiation time one way ANOVA was performed by Origin Pro software.

\section{RESULTS}

There were differences in the frequency of right and left handed subjects among the selected factory workers. The results depicted (Table 2) that among the subjects, 33 were right handed because they had significantly $(\mathrm{P}<0.05)$ higher grip strength in the right hand than the left hand, rest of the subjects were found to be left handed having significantly higher $(\mathrm{P}<0.05)$ grip strength in the left hand than the right hand .

Table 2: Hand grip strength of right and left hand of right handed $(n=33)$ and left handed factory workers $(n=11)$

\begin{tabular}{|l|l|l|}
\hline Parameter & Right hand (mean \pm SD) & Left hand (mean \pm SD) \\
\hline $\begin{array}{l}\text { Hand grip strength }(\mathrm{kg}) \text { of right handed } \\
\text { factory workers }\end{array}$ & $36.1 \pm 9.4$ & $34.8 \pm 9.6^{*}$ \\
\hline $\begin{array}{l}\text { Hand grip strength }(\mathrm{kg}) \text { of left handed } \\
\text { factory workers }\end{array}$ & $28.3 \pm 6.3$ & $30.6 \pm 7.2^{*}$ \\
\hline
\end{tabular}

*with respect to right hand $\mathrm{P}<0.05$

Right handed and left handed subjects were compared for motion stereotypic responses at resting condition. The results of this comparison were illustrated in Table 3 and Table 4. It was found that for vertical, horizontal and circular displays, both right and left handed subjects had the same direction of motion for the operations of controls. Clockwise to right and anticlockwise to 
left stereotypes were dominant for horizontal display and for vertical display clockwise to up and anticlockwise to down stereotypes were dominant where as for circular display clockwise for clockwise and anticlockwise for anticlockwise motion stereotypes were found to be dominant for both groups. For horizontally aligned rocker switch for the operation of electric light unit, 'right' to 'on the light' stereotype was dominant and for vertically aligned rocker switch 'down' to 'on the light' stereotype was dominant for both right handed and left handed subjects.

Table 3: Comparison of the motion stereotypic responses between right handed and left handed subjects in resting condition for rotary control-analog display operation

\begin{tabular}{|l|l|l|l|l|}
\hline \multirow{2}{*}{$\begin{array}{l}\text { Type of display and } \\
\text { instruction to the subjects }\end{array}$} & \multicolumn{2}{|l|}{$\begin{array}{l}\text { Response pattern of the right } \\
\text { handed subjects (n=33) }\end{array}$} & \multicolumn{2}{l|}{$\begin{array}{l}\text { Response pattern of the left } \\
\text { handed subjects (n=11) }\end{array}$} \\
\cline { 2 - 5 } & CW \% & ACW\% & CW\% & ACW \% \\
\hline $\begin{array}{l}\text { Horizontal display with } \\
\text { rotary switch (move right) }\end{array}$ & 75.75 & 24.25 & $\mathbf{8 1 . 8 2}$ & 18.18 \\
\hline $\begin{array}{l}\text { Horizontal display with } \\
\text { rotary switch } \\
\text { (move left) }\end{array}$ & 12.12 & $\mathbf{8 7 . 8 8}$ & 9.09 & $\mathbf{9 0 . 9 1}$ \\
\hline $\begin{array}{l}\text { Vertical display with rotary } \\
\text { switch (move up) }\end{array}$ & $\mathbf{7 5 . 7 5}$ & 24.25 & $\mathbf{8 1 . 8 2}$ & 18.18 \\
\hline $\begin{array}{l}\text { Vertical display with rotary } \\
\text { switch (move down) }\end{array}$ & 21.21 & $\mathbf{7 8 . 7 8}$ & 18.18 & $\mathbf{8 1 . 8 2}$ \\
\hline $\begin{array}{l}\text { Circular display with rotary } \\
\text { switch (move clock wise) }\end{array}$ & $\mathbf{8 1 . 8 2}$ & 18.18 & $\mathbf{9 0 . 9 1}$ & 9.09 \\
\hline $\begin{array}{l}\text { Circular display with rotary } \\
\text { switch (move anti clockwise) }\end{array}$ & 12.12 & $\mathbf{8 7 . 8 8}$ & 18.18 & $\mathbf{8 1 . 8 2}$ \\
\hline
\end{tabular}

Table 4: Comparison of the motion stereotypic responses between right handed and left handed subjects in resting condition for rocker switch-electric light operation

\begin{tabular}{|c|c|c|c|}
\hline Control-display unit & $\begin{array}{c}\text { Response } \\
\text { preference type }\end{array}$ & $\begin{array}{c}\text { Response (\%) of the } \\
\text { right handed } \\
\text { subjects (n=33) }\end{array}$ & $\begin{array}{c}\text { Response (\%) of the } \\
\text { left handed subjects } \\
\text { (n=11) }\end{array}$ \\
\hline $\begin{array}{c}\text { Horizontally aligned } \\
\text { rocker switches-electric } \\
\text { light }\end{array}$ & Right & 51.52 & 54.55 \\
\cline { 2 - 4 } & Left & 48.48 & 45.45 \\
\hline $\begin{array}{c}\text { Vertically aligned rocker } \\
\text { switches-electric light }\end{array}$ & Down & 72.73 & 63.64 \\
\cline { 2 - 4 } & Up & 27.27 & 36.36 \\
\hline
\end{tabular}


Table 5 represents that mean heart rate of the workers which was found to be higher significantly $(\mathrm{p}<0.001)$ after the scheduled factory work. According to the computed CSI values (Trites et.al., 1993) a classification (Table 1) was done on the basis of their percentile values. According to this CSI classification $27.27 \%$ subjects were found to be under light stress, $45.45 \%$ subjects were in moderate stress and $27.27 \%$ subjects were under high stress (Table 6) after scheduled work at factory.

Table 5: Heart Rate in resting $(n=44)$ and after work $(n=44)$ condition

\begin{tabular}{|l|l|l|}
\hline Parameter & Normal resting & After work \\
\hline Heart rate (beats /min) & $81.87 \pm 11.68$ & $129.59 \pm 26.76 * * *$ \\
\hline
\end{tabular}

$* * *$ w.r.t normal resting $\mathrm{p}<0.001$

Table 6: Percentage of workers under different cardiovascular stress levels

\begin{tabular}{|c|c|c|}
\hline CSI value range & Stress level & No of subjects \\
\hline $\mathbf{1 . 0 0}-\mathbf{4 0 . 3 9}\left(35^{\text {th }}\right.$ percentile value $)$ & Light stress & $27.27 \%$ \\
\hline $\mathbf{4 1 . 0 0}-\mathbf{6 1 . 2 1}\left(70^{\text {th }}\right.$ percentile value $)$ & Moderate stress & $45.45 \%$ \\
\hline $\mathbf{6 2 . 0 0}$ and above & High stress & $27.27 \%$ \\
\hline
\end{tabular}

Table 7 depicted the result of response time of the workers for the operation control initiation time at different stress levels and the analysis of results (one way ANOVA) it was noted that there was a significant difference $(\mathrm{P}<0.001)$ of response initiation time among the workers at different stress levels. It was revealed that the mean response initiation time decreased significantly with the gradual increase of stress level.

Table 7: Response initiation time (ms) for control display operation at different stress levels

\begin{tabular}{|c|c|c|}
\hline Stress level & $\begin{array}{c}\text { Response initiation time } \\
\text { (Mean } \pm \text { SD) }\end{array}$ & F value \\
\hline Light stress & $993.83 \pm 2.98$ & \\
\hline Moderate stress & $806.42 \pm 4.58$ & \\
\hline High stress & $707.42 \pm 5.87$ & \\
\hline
\end{tabular}

\#\#\# (P<0.001) 
The stereotypic responses recorded from these three groups of subjects were compared and presented in Table 8. In case of operation of rotary switch and horizontal display unit, when the subjects were asked to move the indicator towards right, a clockwise response was found to be dominant for the subjects with light and moderate stress condition, but in high stress condition the subjects showed a change in the direction of motion stereotype. About $75 \%$ of the workers, who were under high work stress, moved the rotary switch in the anticlockwise direction. From the Chi square test results it was noted that the frequency of stereotype responses was significantly different $(\mathrm{P}<0.05)$ among three groups of workers. However, when they were asked to move the indicator towards left, the dominance of anticlockwise movement was found in all the groups and no statistically significant difference was found in the responses. For the operation of rotary switch and vertical display unit, when the subjects were asked to move the indicator upward, the dominance of clockwise movement was found in light and high stress conditions (75\% and $66.67 \%$ respectively) but for the subjects under moderate stress, the direction of movement stereotype was changed. About $85 \%$ of the subjects operated the control in anticlockwise direction. For this unit when the subjects were asked to move the indicator to downward direction, $75 \%$ of the subjects under light stress and $85 \%$ subjects under moderate stress preferred anticlockwise movement while $83.33 \%$ subjects under high stress condition performed clockwise movement. These differences were found to be significant $(\mathrm{P}<0.01)$ statistically. For the operation of rotary switch and circular display unit, about $75 \%$ of the subjects under light stress and 90\% subjects under moderate stress had moved the indicator in clockwise direction when the subjects were asked to move the indicator in clockwise direction. On the other hand $83.33 \%$ subjects under high stress operated the switch anticlockwise direction in the said operation. This difference in the responses was statistically significant $(\mathrm{P}<0.01)$. For this same unit when the subjects were asked to move the indicator in anticlockwise direction , $83.33 \%$ of the subjects under light stress and $66.67 \%$ subjects under high stress preferred to move the switch in anticlockwise manner but $90 \%$ of the subjects under moderate stress selected clockwise movement. This difference in the responses of the workers was also statistically significant $(\mathrm{P}<0.001)$. 
Table 8: Direction of motion stereotypes for different sets of rotary control- display units (Analog) at different level of stress

\begin{tabular}{|c|c|c|c|c|c|c|c|}
\hline \multirow[t]{2}{*}{$\begin{array}{l}\text { Type of display } \\
\text { and instruction to } \\
\text { the subjects }\end{array}$} & \multicolumn{2}{|c|}{$\begin{array}{l}\text { Response pattern } \\
\text { in light stress } \\
(n=12)\end{array}$} & \multicolumn{2}{|c|}{$\begin{array}{l}\text { Response } \\
\text { pattern in } \\
\text { moderate stress } \\
(n=20)\end{array}$} & \multicolumn{2}{|c|}{$\begin{array}{l}\text { Response } \\
\text { pattern in high } \\
\text { stress }(n=12)\end{array}$} & \multirow{2}{*}{$\begin{array}{l}\text { Chi square } \\
\text { test (level } \\
\text { of } \\
\text { significance } \\
\text { ) }\end{array}$} \\
\hline & $\begin{array}{l}\text { CW } \\
(\%)\end{array}$ & $\begin{array}{l}\text { ACW } \\
(\%)\end{array}$ & $\begin{array}{l}\text { CW } \\
\text { (\%) }\end{array}$ & $\begin{array}{l}\text { ACW } \\
(\%)\end{array}$ & $\begin{array}{l}\text { CW } \\
(\%)\end{array}$ & $\begin{array}{l}\text { ACW } \\
(\%)\end{array}$ & \\
\hline $\begin{array}{l}\text { Horizontal display } \\
\text { with rotary switch } \\
\text { (move the indicator } \\
\text { right) }\end{array}$ & 75 & 25 & 70 & 30 & 25 & 75 & $\mathrm{P}<0.05$ \\
\hline $\begin{array}{l}\text { Horizontal display } \\
\text { with rotary switch } \\
\text { (move the indicator } \\
\text { left) }\end{array}$ & 33.33 & 66.67 & 20 & 80 & 25 & 75 & NS \\
\hline $\begin{array}{l}\text { Vertical display with } \\
\text { rotary switch(move } \\
\text { the indicator up) }\end{array}$ & 75 & 25 & 15 & 85 & 66.67 & 33.33 & $\mathrm{P}<0.01$ \\
\hline $\begin{array}{l}\text { Vertical display with } \\
\text { rotary switch (move } \\
\text { the indicator down) }\end{array}$ & 25 & 75 & 15 & 85 & 83.33 & 16.67 & $\mathrm{P}<0.01$ \\
\hline $\begin{array}{l}\text { Circular display } \\
\text { with rotary switch } \\
\text { (move the indicator } \\
\text { clockwise) }\end{array}$ & 75 & 25 & 90 & 10 & 16.67 & 83.33 & $\mathrm{P}<0.01$ \\
\hline $\begin{array}{l}\text { Circular display } \\
\text { with rotary switch } \\
\text { (move the indicator } \\
\text { anti clockwise) }\end{array}$ & 16.67 & 83.33 & 90 & 10 & 33.33 & 66.67 & $\mathrm{P}<0.001$ \\
\hline
\end{tabular}

CW- clock wise ACW- anti clockwise

Table 9 illustrated that during operation of horizontally aligned rocker switch with electric light as display unit, it was noted that $58.33 \%$ of subjects under light stress and $100 \%$ subjects under high stress had chosen to press right end of the switches to make the light 'on' but $75 \%$ subject under moderate stress had chosen to press left end for the same movement. This difference in the direction of motion elicited by the workers was statistically significant $(\mathrm{P}<0.01)$. For vertically aligned rocker switch with electric light as display unit, the subjects of all the three groups (58.33\%, 65\% and 66.67\% with light , moderate and high stress respectively) found to press the down end of the switch to make the light 'on'. So, there was no significant difference in the direction of movement among three groups of factory workers. 
Table10 represented the comparison of index of reversibility (IR) for rotary control- display units at different stress levels. The results showed that reversibility was altered for each stress level for all the three rotary control-display units. For rotary control with vertical display and rotary control with circular display units, the IR was high (0.625 and 0.667 respectively) in case of light stress but for rotary control with horizontal display in case of moderate stress, the IR was found to be high (0.620).

Table 9: Direction of motion stereotypes for different sets of Rocker switch at different stress levels

\begin{tabular}{|c|c|c|c|c|c|}
\hline $\begin{array}{c}\text { Control-display } \\
\text { unit }\end{array}$ & $\begin{array}{c}\text { Response } \\
\text { preference } \\
\text { type }\end{array}$ & $\begin{array}{c}\text { Response } \\
(\%) \text { in light } \\
\text { stress } \\
(n=12)\end{array}$ & $\begin{array}{c}\text { Response } \\
(\%) \text { in } \\
\text { moderate } \\
\text { stress }(n=20)\end{array}$ & $\begin{array}{c}\text { Response } \\
(\%) \text { in high } \\
\text { stress }(n=12)\end{array}$ & $\begin{array}{l}\text { Chi square } \\
\text { test (level of } \\
\text { significance) }\end{array}$ \\
\hline \multirow{2}{*}{$\begin{array}{c}\text { Horizontally } \\
\text { aligned rocker } \\
\text { switches-electric } \\
\text { light }\end{array}$} & $\begin{array}{c}\text { Towards } \\
\text { Right }\end{array}$ & 58.33 & 25 & 100 & \multirow[t]{2}{*}{$\mathrm{P}<0.01$} \\
\hline & $\begin{array}{c}\text { Towards } \\
\text { Left }\end{array}$ & 41.67 & 75 & 0 & \\
\hline \multirow{2}{*}{$\begin{array}{l}\text { Vertically aligned } \\
\text { rocker switches- } \\
\text { electric light }\end{array}$} & Downward & 58.33 & 65 & 66.67 & \multirow[t]{2}{*}{ NS } \\
\hline & Upward & 41.67 & 35 & 33.33 & \\
\hline
\end{tabular}

NS - not significant

Table 10: The indexes of reversibility (IR) for all the control-display configurations in normal and stress conditions

\begin{tabular}{|l|l|l|l|}
\hline $\begin{array}{l}\text { Control-display } \\
\text { configurations }\end{array}$ & $\begin{array}{l}\text { Index of } \\
\text { reversibility (IR) } \\
\text { (light stress) }\end{array}$ & $\begin{array}{l}\text { Index of } \\
\text { reversibility (IR) } \\
\text { (moderate stress) }\end{array}$ & $\begin{array}{l}\text { Index of } \\
\text { reversibility (IR) } \\
\text { (high stress) }\end{array}$ \\
\hline $\begin{array}{l}\text { Rotary control -horizontal } \\
\text { display }\end{array}$ & 0.583 & 0.620 & 0.375 \\
\hline $\begin{array}{l}\text { Rotary control -vertical } \\
\text { display }\end{array}$ & 0.625 & 0.255 & 0.388 \\
\hline $\begin{array}{l}\text { Rotary control -circular } \\
\text { display }\end{array}$ & 0.667 & 0.180 & 0.388 \\
\hline
\end{tabular}

\section{DISCUSSION}

The results revealed that work at pole factory imposed stress on the workers. CSI classification showed that the stress imposed on the subject after the same work schedule were not similar and this finding may be supported by a report of National Association of Mental Health (2005) which illustrated that individuality and the approach of coping of the workers can affect the outcome of 
stress. So it may be said that same amount of work load or stressor can cause stress which may vary individual to individual.

In this study it was found that due to the work stress the heart rate of the workers were significantly increased. The same fact was reported in some other studies (Dawans et. al., 2011; Vrijkotte, et al., 2000; Lundberg, et al., 1996). Stressful conditions may trigger stress hormone release, which in turn increase the heart rate (Lupen et. al., 2006). The stress hormone epinephrine can be taken as an example which works through binding with beta-1 adrenergic receptors at the SA node of the heart to elevate heart rate (Raff \& Levitzky, 2011).

It was noted that there was no significant difference between the motion stereotypic responses of right and left handed workers for operation of all the control-display units. Similar finding was suggested by Simpson and Chan (1988) where they found no significant differences between left-handed and right-handed subjects with any of the control-display relationships they studied. Porac and Searleman (2002) also showed the absence of association of handedness with cognitive performance in their study. It might be due to the fact that most of the products manufactured today are designed for the right-handed population and left-handed users need to get used to. So, the finding of no difference between the response of right-handed and lefthanded workers may be an indication of that adaptation.

This study opened up the fact that increased stress level altered the direction of motion stereotype. In high and moderate stress the direction of motion stereotype was changed for all the control-display units except for rotary switch unit operation with horizontal display (move to left) and for vertically aligned rocker switch operation with electric light as display where the direction of motion stereotype was similar for all the stress levels. So it can be said that work related stress had a definite impact on the stereotypic response of the subjects. It meant that increased stress at work might alter the cognitive response of an operator. Thus it indicated that altered cognitive response influenced the human- machine interaction during stress condition which might affect performance of the workers. Wastell and Newman (1996) also concluded in their study that a properly designed military system should enhance the performance by lowering the stress of the operator. Schellenkens et. al. (2000) revealed some persistent effect of demanding day long office work on cognition of the workers. According to a report (2007) of the Work Foundation titled 'stress at work', the most persistent factor behind work related stress is work load.

In consideration of the index of reversibility, it was found that the man- machine compatibility of rotary control horizontal display was the lowest in high stress and the highest in light stress. For Rotary control with vertical display and rotary control with circular display the lowest IR was found in moderate stress while the highest IR was found for both the above units in case of light stress. The best configuration of IR found in this study was rotary switch unit with circular display and this finding corroborated with the findings of another study (Chan \& Chan, 2007b). 
So, it can be said that stress had an impact on index of reversibility (IR). Increased stress decreased the IR values. In other words it can be stated that the dominance of stereotypic response for a control-display unit was decreased.

It has been noticed that the response initiation time of the subjects were gradually decreased with increased stress, which meant that the factory workers respond gradually faster to the instructions with an increase in stress. This might be due to the fight-or-flight response, by which our body's sympathetic nervous system reacted to a stressful events, body makes higher amount of the chemicals cortisol, adrenaline and noradrenaline, which in turn trigger higher heart rate and mental alertness which helps to protect ourselves in a stressful situations (Lupen et. al., 2006), so we become more alert and react faster to any stimulus. Davranche et al. (2006) found that due to exercise arousal (state of attention or alertness) increased which improved reaction time. VaezMousavi et. al. (2009) concluded that among some of the participants reaction time was found to be fastest with an intermediate level of arousal (state of attention or alertness), and declines when the subject is either too much relaxed or too much tensed, while others showed the opposite phenomenon , in general, reaction time tended to get better as arousal increased.

\section{CONCLUSIONS}

From this study it can be concluded that increased stress in work place due to the work load may alter direction of motion stereotype of the workers. The direction of motion stereotype may be reversed in case of high work related stress. Response initiation time found to be decreased with increased stress level. However, handedness has no impact on the direction of motion stereotypic responses. Index of reversibility may also be decreased due to increased stress on the workers. So it may be said that stress has an impact on the different aspects of motion stereotype, i.e., response preference, and index of reversibility.

\section{REFERENCES}

Blaug, R., Kenyon, A. \& Lekhi, R. (2007). Stress at work. A report of the work foundation. Retrieved from http://www.theworkfoundation.com/downloadpublication/report/69_69_stress_at_wor k.pdf

Bowman, O.J., \& Katz, B. (1984). Hand Strength and Prone Extension in Right- Dominant, 6 to 9 years old. American Journal of Occupational Therapy, 38, 367-376.

Chan A. H. S., Shum V. W. Y., Law, H. W. \& Hui, I. K.(2003). Precise effects of control position, indicator type, and scale side on human performance. International Journal of Advanced Manufacturing Technology, 22, 380-386.

Chan, W. H. \& Chan, A. H. S. (2007a). Movement compatibility for rotary control and digital display. Engineering Letters, 14(1), 2-7.

Chan, W. H., \& Chan, A. H. S. (2007b). Movement stereotypes for common control-display configurations in human- machine- interface. IAENG International Journal of Computer Science, 33(2), 2-8. 
Charmandari, E., Tsigos, C. \& Chrousos, G. (2005). Endocrinology of the stress response. Annual Reviews of Physiology, 67, 259-284.

Chau, N., Petry, D., Bourgkard, E., Huguenin, P., Remy, E., \& Andre, J.M. (1997). Comparison between Estimates of Hand Volume and Hand Strengths with Sex and Age with and without Anthropometric Data in Healthy Working People. European Journal of Epidemiology, 13, 309-316.

Corbalis, M.C. (2003). From Hand to Mouth: The origins of Language. Princeton. Princeton University Press.

Courtney, A.J. (1994a). Hong Kong Chinese direction-of-motion stereotypes. Ergonomics, 37, 417-426.

Courtney, A.J. (1994b). The effect of scale-side, indicator type, and control plane on directionof-turn stereotypes for Hong Kong Chinese subjects. Ergonomics, 37, 865-877.

Davranche, K., M. Audiffren \& Denjean, A. (2006). A distributional analysis of the effect of physical exercise on a choice reaction time task. Journal of Sports Sciences, 24(3), 323330 .

Dawans, B. von, Kirschbaum, C. \& Heinrichs, M. (2011). The Trier Social Stress Test for Groups (TSST-G): A new research tool for controlled simultaneous social stress exposure in a group format. Psychoneuroendocrinology, 36, 514-522.

Goldstein, D.S., Kopin, I. J. (2007). Evolution of concepts of stress. Stress. 10 (2), 109-120.

Health and Safety Executive. (2015) . work related stress anxity and depression statistics in Great Britain. Retrieved from http://www.hse.gov.uk/statistics/causdis/stress/stress.pdf

Houtman, I. L. D., Bongers, P. M., Smulders, P. G. W., \& Kompier, M. A. J. (1994) Psychosocial stressors at work and neuromuscular problems. Scandinavian Journal of Work, Environment \& Health, 20, 139-145.

Kroemer, K.H.E., \& Grandjean, E. (1997). Fitting the Task to the Human (5 ${ }^{\text {th }}$ ed.), (pp. 172173).CRC Press

Levitzky, M. \& Raff, H. (2011). Medical Physiology: A Systems Approach. McGraw Hill Medical. 27, 268.

Lundberg, U., Kadefors, R., Melin, B., Palmerud, G., Hassmén, P., Engström, M., Elfsberg \& Dohns, I. (1994). Psychophysiological stress and EMG activity of the trapezius muscle. International Journal of Behavioral Medicine, 1, 354-370.

Lupien, S. J., Ouelle-Morin, I., Hupback, A., Walker, D., Tu, M. T. \& Buss, C. (2006). Beyond the stress concept: Allostatic load—a developmental biological and cognitive perspective. In: D. Cicchetti (Ed.), Handbook series on developmental psychopathology (pp. 784809). Wisconsin.

Mind week report. (May, 2005). Stress and mental health in the work place. Retrieved from http://socialwelfare.bl.uk/subject-areas/services-client-groups/adults-mentalhealth/mind/144533Stress_and_MH_in_the_workplace.pdf

Peters, M. (1998). Description and validation of a flexible and broadly usable handedness questionnaire. Laterality, 1, 77-96.

Petropoulos, H. \& Brebner, J. (1981). Stereotypes for direction of- movement of rotary controls 
associated with linear displays, the effects of scale presence and position, of pointer direction and distances between the control and the display. Ergonomics, 24, 143-151.

Porac, C. \& Searleman, A (2002). The effect of hand preference side and hand preference switch history on measures of psychological and physical well-being and cognitive performance in a sample of older adult right and left handers. Neuropsychologia, 40, 2074-2083

Schellenkens, J. M. H., Sijtsma, G. J., Vegter, E. \& Meijman, T. F. (2000). Immediate and delayed after- effect of long- lasting mentally demanding work. Biological Psychology, 53, 37-56

Simpson, G. S., \& Chan, W. L. (1988). The derivation of population stereotypes for mining machines and some reservations on the general applicability of published stereotypes. Ergonomics, 31, 327-335.

Smith, A., Carolyn Brice, C., Collins, A., Matthews, V. \& Rachel McNamara, R. (2000). The scale of occupational stress: A further analysis of the impact of demographic factors and type of job HSE Contract Research Report No. 311/2000. Prepared by: Centre for Occupational and Health Psychology School of Psychology, Cardiff University. Retrieved from http://www.hse.gov.uk/research/crr_pdf/2000/crr00311.pdf

Trites, D.G., Robinson, D.G. \& Banister, E.W. (1993). Cardiovascular and muscular strain during a tree planting season among British Columbia silviculture workers. Ergonomics, 36 (8), 935-949.

VaezMousavi, S. M., Barry, R. J, \& Clarke, A. R. (2009). Individual differences in task-related activation and performance. Physiology and Behavior, 98(3), 326-330.

Vrijkotte, T. G. M., Van Doornen, L. J. P. \& De Geus E. J. C. (2000). Effects of work stress on ambulatory blood pressure, heart rate, and heart rate variability. Hypertension, 35 (4), 880-886.

Wastell, D. G. \& Newman, M. (1996). Stress, control and computer system design: A psychophysiological field study. Behavior \& Information Technology, 15, 183-192.

Weiner, J. S., \& Lourie, J.A. (1981). Practical Human Biology. London. Academic Press. 